\title{
Drift, growth, and survival of larval Northeast Arctic cod with simple rules of behaviour
}

\author{
Frode Vikebø*, Christian Jørgensen, Trond Kristiansen, Øyvind Fiksen
}

Department of Biology, University of Bergen, PO Box 7800, 5020 Bergen, Norway

\begin{abstract}
Due to vertical variations in ocean circulation, larval Northeast Arctic cod Gadus morhua may influence their own drift routes by migrating vertically. By coupling a larval individualbased model and a general circulation model, we simulated larval vertical positioning according to simple rules based on individual risk sensitivity. This enabled us to investigate how larval growth, survival and horizontal distribution vary between individuals following different rules. Immediate depth selection follows from the rules, with implications for environmental exposure and instantaneous growth rates. The behavioural rules had long-term and large-scale consequences, since vertical positioning influences the drift trajectory of the larva, and thereby the physical environment the larva experiences along its way. Two alternative rule formulations were explored, each containing the full range of strategies, from maximising immediate growth to maximising immediate survival. Fitness was defined as accumulated survival probability up to $18 \mathrm{~mm}$ for larvae released at 2 important spawning grounds in the Lofoten area. Both rules gave better fitness than for individuals drifting at fixed depths. The most successful individuals performed active vertical migration and had an intermediate risk sensitivity. When risk sensitivity was allowed to change with ontogeny, larvae that first emphasised growth and then changed to intermediate risk sensitivity were the most successful ones, although improvements were minor compared to fixed sensitivities. The 2 spawning grounds led to slight differences in fitness, but success as a result of risk sensitivity was similar at both, suggesting that optimal larval strategies may be robust across different spawning grounds.
\end{abstract}

KEY WORDS: Individual-based model · Rule-based behaviour - Larval fish · Vertical migration General circulation model · Adaptive behaviour

\section{INTRODUCTION}

Marine larvae of many species have pelagic phases during which they drift apparently haphazardly and arbitrarily through immense water masses. The swimming abilities of millimetre- to centimetre-sized larvae are often limited compared to the force of ocean currents. However, swimming ability normally increases throughout ontogeny (Clark et al. 2005), and may prove significant compared to drift if it is exerted in a non-random direction (Leis et al. 2006). In the present paper, we investigate the effects of vertical migrations, which can dramatically change the life of larvae in 2 important ways (e.g. Santos et al. 2006, Fiksen et al. 2007, this Theme Section [TS]). First, layered currents may carry vertically separated larvae in different directions and at different speeds. Ocean circulation models have shown that drifting particles fixed at depths only $10 \mathrm{~m}$ apart may end up in different oceans when spawned at times and sites typical for Northeast Arctic cod Gadus morhua (Vikebø et al. 2005). Second, light extinction down through the water column results in vertical gradients, in which the top layers have sufficient light for feeding, but also enough to be detected by predators. Only a few tens of metres deeper, the darkness provides a safer refuge from visual predators, but potentially too little light to feed. Additionally, a number of other important environmental variables such as prey density, turbulence and temperature may also vary strongly in the water column, contributing to distinct vertical habitats.

Field observations suggest that larvae perform diurnal vertical migrations (Ellertsen et al. 1984, Neilson \& Perry 
1990, Lough \& Potter 1993). Several models of zooplankton and fish have interpreted such behaviour in relation to predator-prey interactions and the reduction of mortality (Fiksen 1997, Strand et al. 2002, Fiksen et al. 2005). Here, we couple vertical migrations with an ocean circulation model, and evaluate the effects of vertical migration on the ocean transport of larvae. The drift trajectories of eggs and larval fish depend on (1) the time and place of spawning (Hinckley et al. 2001, Mullon et al. 2002, Huggett et al. 2003) and (2) the complex interaction between ocean circulation and individual behaviour throughout ontogeny (Hinckley et al. 1996, Werner et al. 1996, 2001, Hinrichsen et al. 2002, Fox et al. 2006). In turn, this sets premises for individual growth and survival and, ultimately, for recruitment to the stock and contribution to the future gene pool.

Recent developments of ocean circulation models have provided new tools for investigating how organisms are influenced by circulation patterns. However, existing individual-based models (IBM) typically use fixed ad hoc formulations of larval depth positioning. Such imposed behaviours (sensu Grimm \& Railsback 2005) are commonly justified from a set of observations of larval vertical distributions, and may also include observed responses to particular environmental cues such as light. The problems with this procedure are (1) that the ad hoc formulations are based on a limited number of observations and are therefore only valid for the environmental states during these observational periods; at other times there may be environmental cues that could modify or override the imposed behaviour (Neilson \& Perry 1990, Giske et al. 2003), and (2) that the internal physiological condition of an individual typically feeds back on behavioural motivation, hunger and satiation may for example trigger different behaviours under similar environmental conditions (Houston \& McNamara 1999, Clark \& Mangel 2000). Using observations to parameterise important flexible behaviours thus, limits the prognostic value of the model when tested under new environmental conditions.

In addition, contemporary models of larval fish dispersal have only included individuals that vary in spatial position or physiological states. Individual differences or variability in behavioural strategies have so far been ignored (as noted by Huse 2001, Strand et al. 2002). Behaviours such as habitat selection are adaptive traits, evolved under the constraints imposed by the physical and biological environment. A successful larva must grow, survive and end up in favourable nursery areas, and, since their parents have succeeded, offspring that inherit their parents' behavioural strategies may also stand a fair chance of success (Fiksen et al. 2007).

Vikebø et al. (2005) demonstrated that the vertical distribution of larval cod influenced their drift trajectory and temperature exposure, which, in turn, has signifi- cant implications for growth and survival. However, the model did not take active larval migration, feeding, or predation risks into consideration. In the present paper, we include these factors and allow larvae to choose depth according to a rule-based risk sensitivity specific for each individual. In the simplest version, a single parameter determines how risk sensitive the larvae are. Larvae with a low risk sensitivity select a vertical habitat where growth is favourable and, consequently, mortality is high. Since currents change with depth, the vertical position has consequences for the drift trajectory the larvae follow. In this way, the behavioural strategy has both local effects on growth and mortality, as well as long-term and large-scale effects on dispersal and temperature along the drift route. We also explore a 3-parameter version of this strategy, whereby the first 2 parameters represent risk sensitivity in early and late ontogeny, while the third parameter determines when to switch between the 2 behavioural strategies. Finally, we compare the 2 rules with non-responsive individuals that stay at fixed depths.

This paper investigated the combined effects of vertical migration and ocean circulation on growth, mortality and dispersal of larval Northeast Arctic cod. More specifically, we asked the following questions: Does vertical migration increase survival throughout the larval period? How risk sensitive should the larvae be in order to maximise their probability of survival? How does risk sensitivity in the local water column affect long-term dispersal, growth and survival? Should risk sensitivity change as the larvae grow larger? And, should behaviour be different for larvae spawned in an embayment compared with larvae spawned at a more exposed location on the shelf?

\section{METHODS AND MODELS}

To assess the success of the rules, we used the accumulated mortality rate up to a given length. The rationale for this measure is that all individuals have to grow through the larval sizes to reach juvenile and adult life stages. From a life-history perspective, the only reason to stop growth would be to start reproduction. We only modelled larval cod far below the earliest observed maturation size for this species. The success of a behavioural strategy in these early life stages can therefore be summarised as the probability with which it survives until a given size-for us limited to $18 \mathrm{~mm}$, as this is the maximum size to which the physiological submodels remain valid.

The ocean model. The numerical ocean model used in this study was the ROMS Version 2.0 (Ezer et al. 2002, Shchepetkin \& McWilliams 2003, Shchepetkin \& McWilliams 2005, available at www.myroms.org). The 
model setup was similar to that described by Vikebø et al. (2005). Lateral boundary conditions were taken from a monthly mean climatology (Engedahl et al. 1998), while the mean daily vertical boundary conditions (air pressure, wind stress and heat flux) were taken from the NCEP/NCAR database (Kalnay et al. 1996) for the year 1985.

In Vikebø et al. (2005), the particle dispersion was run simultaneously ('online'), as a subroutine within the ocean model. However, the present exploration of behavioural strategies required much more CPU time, and particle dispersion was therefore detached ('offline'). The Lagrangian particle-tracking model (LADIM; Ådlandsvik \& Sundby 1994) has a time step of $1 \mathrm{~h}$, while the current and hydrography fields from the ocean model are daily averages. Multilinear interpolation provides necessary input for the dispersal of particles by use of a fourth order Runge Kutta advection scheme (Ramsden \& Holloway 1991).

The range of resolved eddies and velocity shear is proportional to the spatial resolution of the ocean model. Hence, with increasing spatial resolution, the need for additional parameterised diffusion, e.g. random walk, is reduced. Ådlandsvik \& Sundby (1994) used a spatial resolution of $20 \mathrm{~km}$ and included a random component for parameterising a Fickian diffusion of $100 \mathrm{~m}^{2} \mathrm{~s}^{-1}$. In the current model setup the horizontal resolution ranged from 3.5 to $8 \mathrm{~km}$, moving from the upstream to the downstream boundary. We therefore did not include any random walk, although this omission will cause an underestimation of dispersal.

The individual-based model. Model organism: The larvae were characterised by standard length $L(\mathrm{~mm})$, body mass $w$ (dry weight, mg), spatial coordinates $(x, y, z)$ and accrued probability of survival $P$ s since hatching. The attribute vector of individual $i$ at time $t$ was thus:

$$
A_{i, t}=\left(L_{i}, W_{i}, X_{i}, y_{i}, z_{i}, P \mathrm{~s}_{i}\right)
$$

The attributes were updated by local growth, mortality and velocity field at each time increment $t(1 \mathrm{~h})$ of the model. Growth and mortality were driven by light, the modelled temperature field and body size. Only horizontal velocities were considered for the advection of individuals, though the larva itself was allowed to migrate vertically at a velocity of $1 / 3 \mathrm{~L} \mathrm{~s}^{-1}$. Hence, the swimming capabilities of newly hatched larvae and of the largest larvae $(18 \mathrm{~mm})$ were about 4 and $22 \mathrm{~m} \mathrm{~h}^{-1}$, respectively. With a daily vertical migration distance of up to $40 \mathrm{~m}$ and a time step in the IBM of $1 \mathrm{~h}$, newly hatched larvae were therefore constrained by their ability to choose habitat based on potential growth and survival, while the large larvae were not.

It was essential for the model that growth and mortality rates emerge from habitat selection, which was specified by the behavioural rule. We used survival up to $18 \mathrm{~mm}$ length as a measure of fitness, since all individuals have to grow through this size to reach juvenile and adult life stages. We assumed that larvae can sense or assess growth opportunity and mortality risk in the upper $100 \mathrm{~m}$ of the water column, but that they are not able to make predictions for the future. How behaviour will change under limited information is a topic for future studies, for example, if larvae can only assess growth and mortality within their potential swimming range or in water bodies they have passed through. All larvae were initialised at the same size $(0.03 \mathrm{mg}$, $3.53 \mathrm{~mm}$ : the same initial weight as in Otterlei et al. 1999) and at a fixed depth (1 m). We released larvae at Moskenesgrunnen and in the Vestfjorden, 2 important spawning grounds in the Lofoten region, at times near the peak spawning period, covering $4 \times 3$ grid cells or about $20 \times 15 \mathrm{~km}$ (Fig. 1). Initiating larvae with spatial

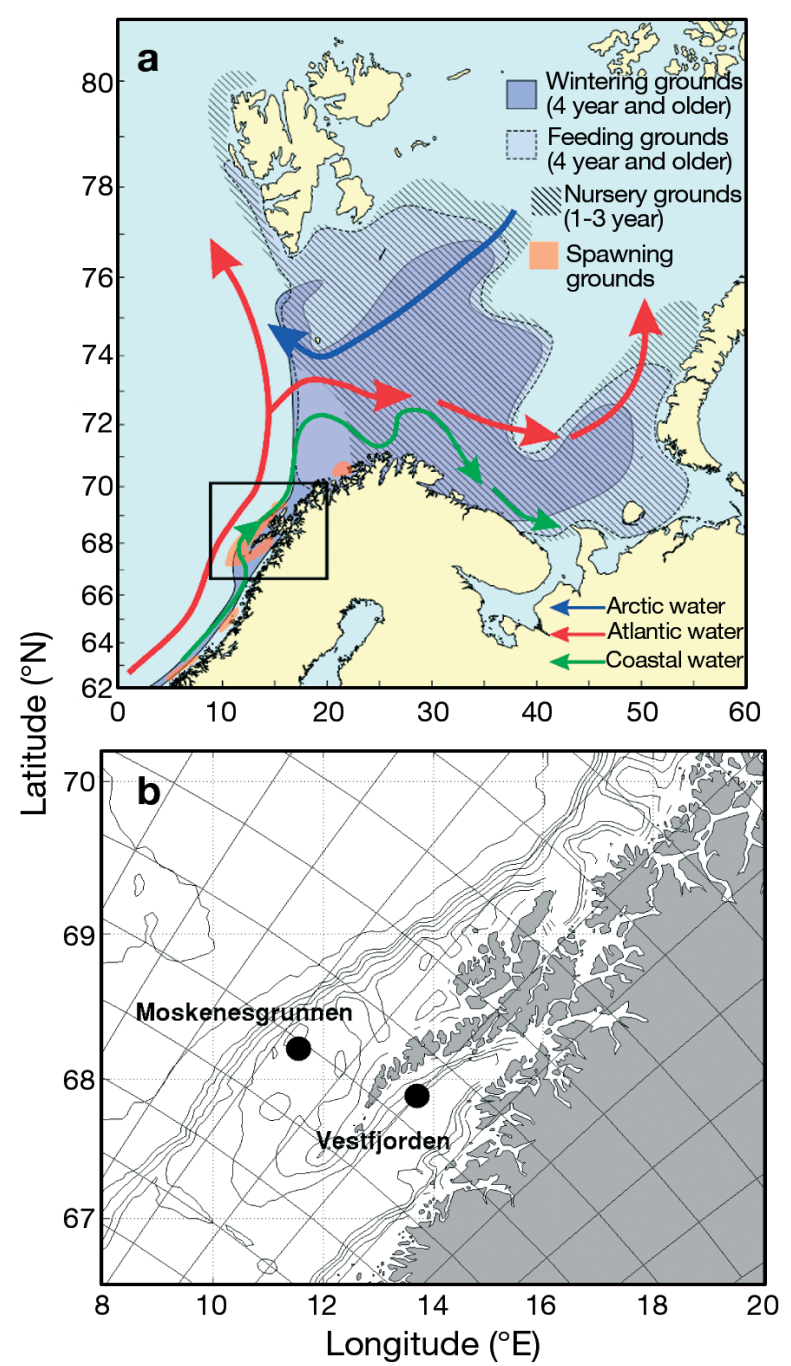

Fig. 1. (a) Spawning and nursery grounds of Northeast Arctic cod Gadus morhua in relation to different water masses. (b) The 2 spawning grounds included in this study. Curved grid delineates $10 \times 10$ grid cells 
variation within these cells introduced divergence in larval trajectories due to horizontal velocity shear.

Submodels: Growth: The maximum specific growth rate $G\left(w_{1} T_{z}\right)$ is an empirical function of larval body mass $W$ and ambient temperature $T_{z}$ for larvae fed ad libitum and reared under laboratory conditions (Folkvord 2005). Larval cod have high growth rates, and substantial food intake is required to sustain these rates. Their visual foraging mode makes feeding highly dependent on ambient light $I_{z}$ (Fiksen et al. 1998, Fiksen \& MacKenzie 2002), and this may constrain growth. To include food-limited growth and additional energetic costs, we added standard metabolic rate $\operatorname{SMR}\left(w, T_{z}\right)$ to the estimated growth potential, limited this by food availability (we have not included prey explicitly here, food availability is dependent on light) and then subtracted the SMR (see Fiksen \& Folkvord 1999). The standard metabolic rate of larval cod was estimated by Finn et al. (2002), and we applied their estimate here. Additional energetic costs, such as swimming costs $\mathrm{SC}(w, \Delta z)$ depending on body size $w$ and migration distance per time $\Delta z$, were subtracted from the potential growth rate. The realised growth rate $g_{z}\left(\mathrm{~s}^{-1}\right)$ of a larva was thus a function of body mass $W$, temperature $T_{z}$, light $I_{z}$ and swimming activity $\Delta z$, such that:

$$
\begin{aligned}
g_{z}(w, \Delta z) & =\left[G\left(w, T_{z}\right)+S M R\left(w, T_{z}\right)\right] \cdot\left(1-e^{-10 \frac{1_{z}}{K_{e}+I_{z}}}\right) \\
& -S M R\left(w, T_{z}\right)-S C(w, \Delta z)
\end{aligned}
$$

The parameter $K_{e}$ (determining food limitation with light) was set to $1 \mu \mathrm{mol}$ photons $\mathrm{m}^{-2} \mathrm{~s}^{-1}$ as in Fiksen \& MacKenzie (2002), and the coefficient 10 was chosen arbitrarily to limit growth rates at depths below $\sim 50 \mathrm{~m}$, where zooplankton availability (prey densities and light) is normally low. Swimming costs $\mathrm{SC}(w, \Delta z)$ were included as a maximum of $10 \%$ of SMR at a fixed temperature $\left(7^{\circ} \mathrm{C}\right)$ if the larvae swim up or down at a velocity of $1 / 3 L^{-1}$, linearly decreasing with swimming speed or migration range $(\Delta z)$. This meant that specific swimming costs decreased slightly with body mass. Growth was represented more simplistically here than by Kristiansen et al. (2007), to reduce the CPU time required for the high number of particles.

Predation: Larval fish are subject to predation from both invertebrates and fish (Bailey \& Houde 1989). Typically, vulnerability to invertebrate predators decreases with larval size as they outgrow abundant, smaller ambush and cruising zooplankton predators. On the other hand, the efficiency of piscivores is very sensitive to detection distance, which increases with light and larval size (Aksnes \& Giske 1993, Aksnes \& Utne 1997). Larvae may therefore become more vulnerable to fish predators with size, unless behavioural strategies such as vertical migration offset increases in encounter rates.
We modelled predation from fish and invertebrates separately, similar to procedures described by Fiksen et al. (2002). Predation rate from invertebrates $\mu_{n}\left(h^{-1}\right)$ decreases with larval body length $L(\mathrm{~mm})$ as $\mu_{\mathrm{n}}=$ $0.01 L^{-1.3}$. Predation rate from fish is $\mu_{\mathrm{f}}=0.05 R^{2}$, where $R$ is the piscivore's sighting distance of a larva depending on light and larval size and the coefficient summarises all factors such as fish density and escape probability (see Fiksen et al. 2002 for details). The total instantaneous mortality rate $M_{z}=\mu_{\mathrm{n}}+\mu_{\mathrm{f}}$ is then a function of depth, surface irradiance and larval size. Little knowledge exists on how mortality risks are divided between invertebrates and fish for larvae, but this simple model captures some essential factors such as body size and light.

Light: Light is a crucial factor for both growth and mortality rates. We modelled surface light as a function of latitude, day of year and time of day (Skartveit \& Olseth 1988), and assumed vertical light attenuation according to the Lambert-Beer law, with a diffuse attenuation coefficient of $0.18 \mathrm{~m}^{-1}$ and a maximum (midday) surface irradiance of $500 \mu \mathrm{mol}$ photons $\mathrm{m}^{-2} \mathrm{~s}^{-1}$.

Behavioural rules: Individuals follow a simple rule to select vertical position (Fiksen et al. 2007). We assumed that larvae have complete information about depth-dependent growth $g_{z}$ and mortality $m_{z}$ within the upper $100 \mathrm{~m}$. The larva then decides on the next depth $z_{i}^{*}(t)$ from:

$$
z_{i}^{*}(t)=\max _{z}\left[\left(1-\pi_{i}\right) g_{z}-\pi_{i} m_{z}\right]
$$

where $0 \leq \pi_{i} \leq 1$ is the behavioural strategy of individual $i$ and $\pi$ can be interpreted as the individual's risk sensitivity. A low $\pi_{i}$ characterises an individual always maximising instantaneous growth, and a high $\pi_{i}$ characterises an individual maximising instantaneous survival. Individuals with high $\pi_{i}$ thus can be interpreted as being fearful, and those with low $\pi_{i}$ as being bold. The risk sensitivity of the individual thus colours its vertical migration behaviour, with major consequences for growth, mortality and drift trajectory. The rule makes larval habitat selection sensitive to local environmental variability in growth and mortality rates, while the simple formulation of the strategy mimics the genetic predispositions of individuals and can be subject to natural selection over generations.

We tested 2 alternative ways of coding risk sensitivity $\pi_{i}$. The first (Rule 1 ) was simply a fixed genetic value $\pi_{i}$, as described above. We tested the following values for $\pi_{i}: 0,0.01,0.1,0.25,0.5,0.75,0.9,0.98,0.995$, $0.997,0.998,0.999$ and 1 . The second (Rule 2 ) included 2 risk-sensitivity parameters, $\pi 1_{i}$ and $\pi 2_{i}$, one for early and one for the late part of ontogeny. A third parameter determined the size at which the individual switched between the 2 risk sensitivities. This rule allowed risk sensitivity to change ontogenetically. We 
tested combinations of parameter values with the same resolution of $\pi 1_{i}$ and $\pi 2_{i}$ as for Rule 1 , and with the following values for the size $\lambda_{i}$ at which risk sensitivity switches (in mm): 4, 6, 8, 10, 12, 14, 16 and 18 .

Fitness was then evaluated as the total survival probability from early larval phase to $18 \mathrm{~mm}$. Within this range, all our empirical submodels remained valid, and most larvae with positive growth reached this size within the simulation time of $100 \mathrm{~d}$.

\section{RESULTS}

First, we present some of the individual trajectories and dispersal patterns of single individuals released at the same time and from the same position, but with differing behavioural strategies. Then, we investigate emergent patterns by releasing a large number of larvae with various strategies that differ in their risk sensitivities. Finally, we look at the fitness consequences that emerge from behavioural rules over the full range of possible values and with drift stochasticity resulting in variability among individuals.

\section{Individual trajectories and dispersal patterns}

The first numerical experiment tracked a few larvae with different risk sensitivities (Rule 1) released in Vestfjorden and at Moskenesgrunnen (see Fig. 1). The geographical dispersal trajectories of individual larvae (Fig. 2a,b) were determined by interactions between the risk sensitivity of their behaviour and ocean circulation. Larvae with low risk sensitivity $\left(\pi_{i}=0.01\right)$ emphasised immediate growth and tended to remain near the surface throughout the simulation period (Fig. 2c,d). A consequence of this behaviour was that they were captured by the warmer Atlantic currents (Fig. 1b), drifted towards the more central parts of the Barents Sea and reached high growth rates. Larvae with high risk sensitivity $\left(\pi_{i}=0.99\right)$ sought out deep waters, grew slowly and remained in the colder coastal current. Larvae with intermediate risk sensitivity $\left(\pi_{i}=\right.$ 0.5) tended to move deeper with time, and, maybe surprisingly, decreased their range of diel migration (Fig. 2c,d). This was mainly driven by increasing day length, which influences predation risk during the night. Together with the absence of food below $50 \mathrm{~m}$, this created a narrow vertical window (30 to $40 \mathrm{~m}$ ) in which growth and mortality were acceptable. Larvae with intermediate risk sensitivity drifted in warm Atlantic water (Fig. 2f) into the Barents Sea from Moskenesgrunnen, but they drifted in cold coastal water (Fig. 2e) when released in Vestfjorden. These different trajectories significantly affected their respec- tive growth histories (Fig. 2g,h). The purely sizedependent mortality rate decreased rapidly as the larvae grew, while mortality from visual predators increased due to larger size and longer days (Fig. 2i,j). This exemplifies the interaction between spawning strategy (parental decisions on timing and location of spawning) and larval behaviour. A robust larval strategy should therefore be one that functions well across the range of parental spawning strategies.

\section{Emergent dispersal patterns from various risk sensitivities}

To further explore the effects of risk sensitivity (Rule 1) and spawning location, we released 50 individuals at each of 13 levels of risk sensitivity, simultaneously at the 2 locations. The individuals were released twice, $3 \mathrm{~d}$ before and $3 \mathrm{~d}$ after the time of peak spawning in Northeast Arctic cod, with minor spatial perturbations around the spawning grounds. The strategies covered a range of possible vertical habitats, illustrated for single individuals released at the 2 spawning grounds for each of the 13 levels of risk sensitivity (Fig. 3). Although the general trend was to move deeper with time, this depended considerably on the growth potential in the water column. The transition to deeper habitats was quite abrupt for risk-averse strategies, leading larvae below $50 \mathrm{~m}$ where there is no food and growth was negative. Remaining constantly at these depths led to starvation, and larvae using such strategies consequently had low fitness. Some individuals encountered stratified water masses, which made growth sufficiently profitable near the surface to offset the increased risk associated with these habitats.

The consequences of individual trajectories on largescale dispersal became apparent when 50 individuals were released with the same risk sensitivity and at the same spawning ground (Fig. 4). First, even minor perturbations around any given release point led to substantial spatial spread in larvae after $100 \mathrm{~d}$, despite the deterministic scheme of particle tracking. Second, individuals originating from Moskenesgrunnen seemed to disperse more than those from Vestfjorden and tended to be more easterly distributed, independent of risk sensitivity. Third, bolder, growth-maximising individuals (low $\pi_{i}$ ) tended to disperse into the central parts of the Barents Sea from both spawning sites.

\section{Fitness consequences of rules and spawning area}

At each level of risk sensitivity, we tracked 50 individuals to $18 \mathrm{~mm}$ length and assessed accrued probability of survival (fitness). These values are presented, 

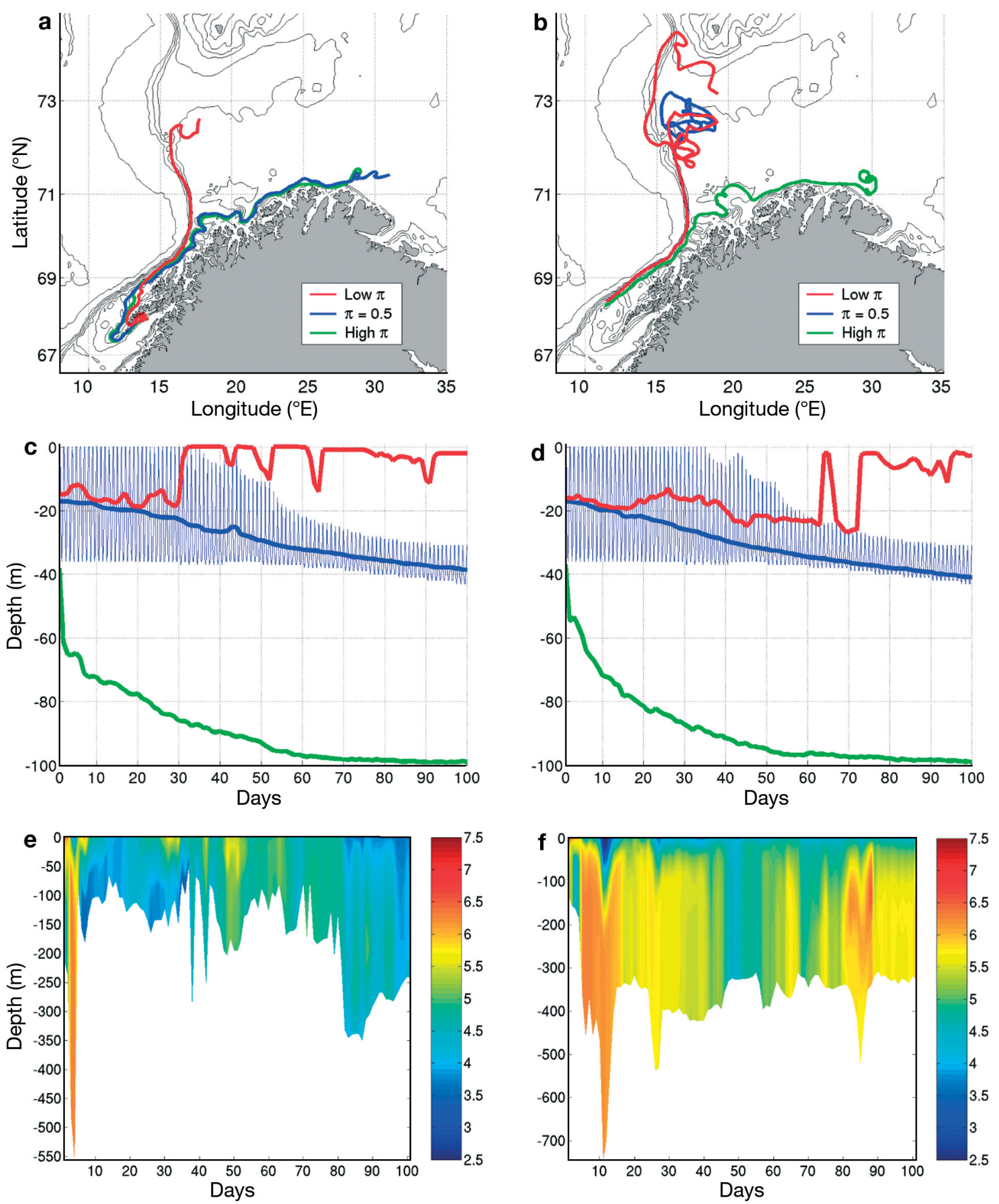

Fig. 2. Gadus morhua. An illustration of $(\mathrm{a}, \mathrm{b})$ dispersal, $(\mathrm{c}, \mathrm{d})$ daily mean depth and $(\mathrm{e}, \mathrm{f})$ temperature profiles along the drifttrajectories of larvae released in Vestfjorden (sheltered spawning ground; left panels) and at Moskenesgrunnen (offshore spawning ground; right panels). Dispersal and mean daily vertical depth for single individuals using Rule 1 for 3 strategies of risk sensitivity are included ( $\pi_{i}=0.01,0.5$ or 0.99 ). Depth is shown with hourly resolution for $\pi_{i}=0.5$ (to illustrate diel migration patterns), but only mean daily depth is shown for $\pi_{i}=0.01$ and 0.99 . Temperature profiles are shown for individuals with $\pi_{i}=0.5$. 'Fearful' larvae (high $\pi_{i}$ ) give immediate survival high priority, migrate deeper, and drift closer to the coast. Also included are hourly ( $\mathrm{g}$,h) ambient temperature and growth history and $(i, j)$ mortality rates from fish $\left(\mu_{f}\right)$ and invertebrates $\left(\mu_{n}\right)$ 

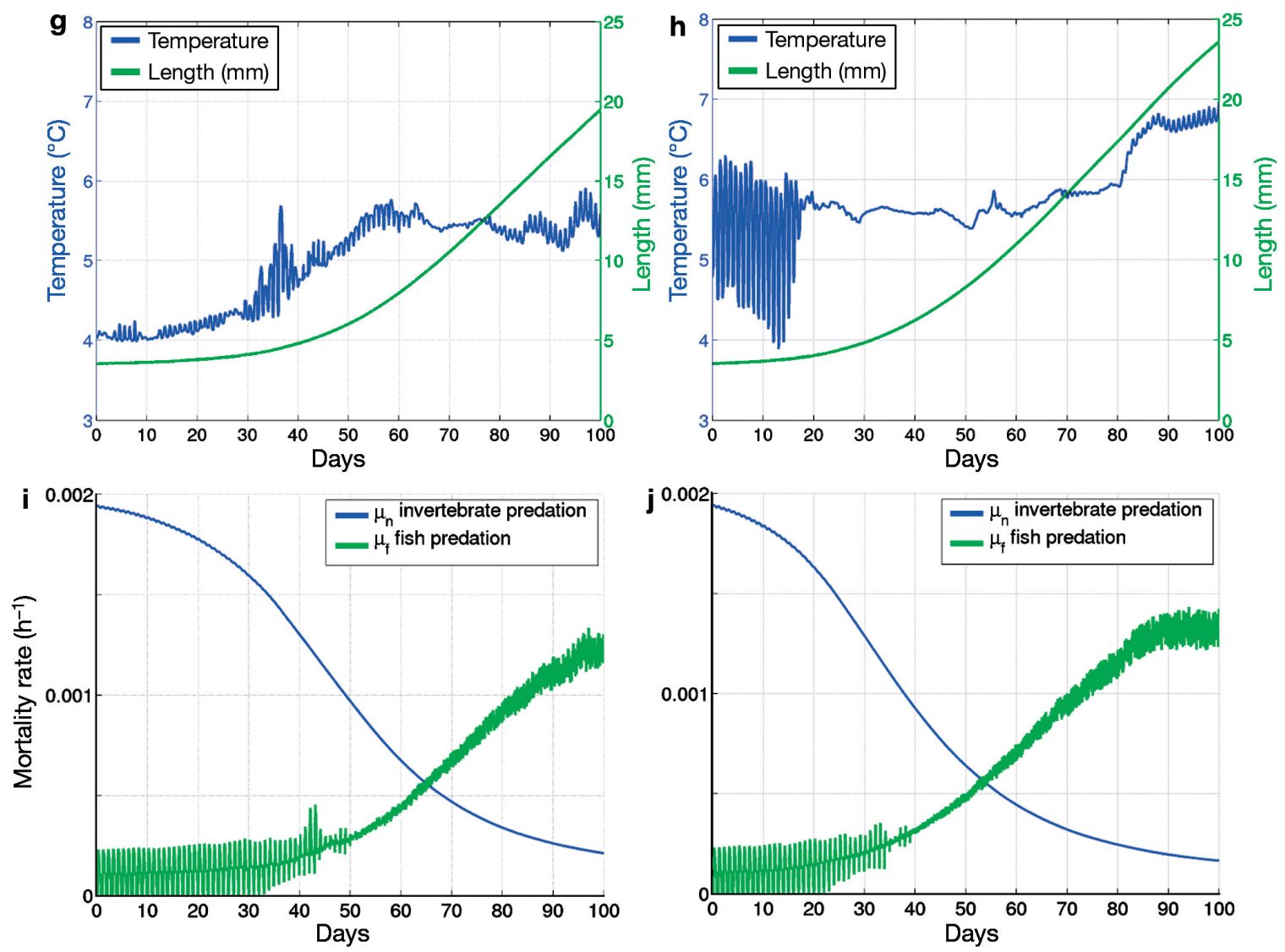

Fig. 2 (continued)

for each of the spawning sites, for the larvae with maximum fitness at each level of risk sensitivity, the average of the most successful 10 and $25 \%$, and the total average (Fig. 5a). This will indicate how robust the different behaviours are in a fitness perspective. Finally, this is compared with survival up to $18 \mathrm{~mm}$ of larvae remaining at fixed depths (Fig. 5b).

Larvae with intermediate risk sensitivity (0.5 to 0.75 ) had the highest survival. They performed vertical, diurnal migrations, increasing towards an average depth of between 30 and $50 \mathrm{~m}$ in late ontogeny (Fig. 2c,d). Larvae with rule-based behaviour generally did better than larvae staying at fixed depths. Also, larvae from Moskenesgrunnen tended to do better than larvae from Vestfjorden in all these realisations, although less so for larvae staying at fixed depths. Note that larvae drifting at a fixed depth of $30 \mathrm{~m}$ achieved higher survival than larvae further up in the water column. Clearly, higher temperatures and enhanced feeding near the surface, which reduces the time needed to reach a length of $18 \mathrm{~mm}$, did not compensate for the increased mortality. Larvae with a high level of risk sensitivity (>0.75) had low (or negative) growth and were unable to reach $18 \mathrm{~mm}$.

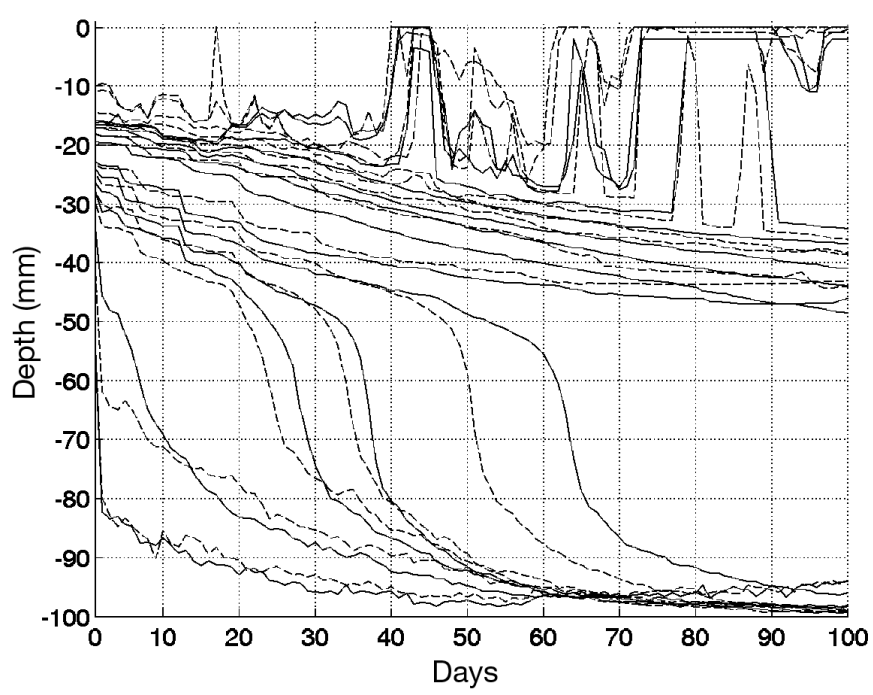

Fig. 3. Gadus morhua. Mean daily vertical positioning for single larvae released at the same time and place in Vestfjorden (broken lines) and Moskenesgrunnen (solid lines) for 13 values of $\pi_{i}(0,0.01,0.1,0.25,0.5,0.75,0.9,0.98,0.995,0.997$, $0.998,0.999,1)$. Increasing risk sensitivity $\left(\pi_{i}\right.$-value) takes larvae deeper. In addition, they move deeper with time due to increasing size (increased susceptibility to visual predation) and longer days 

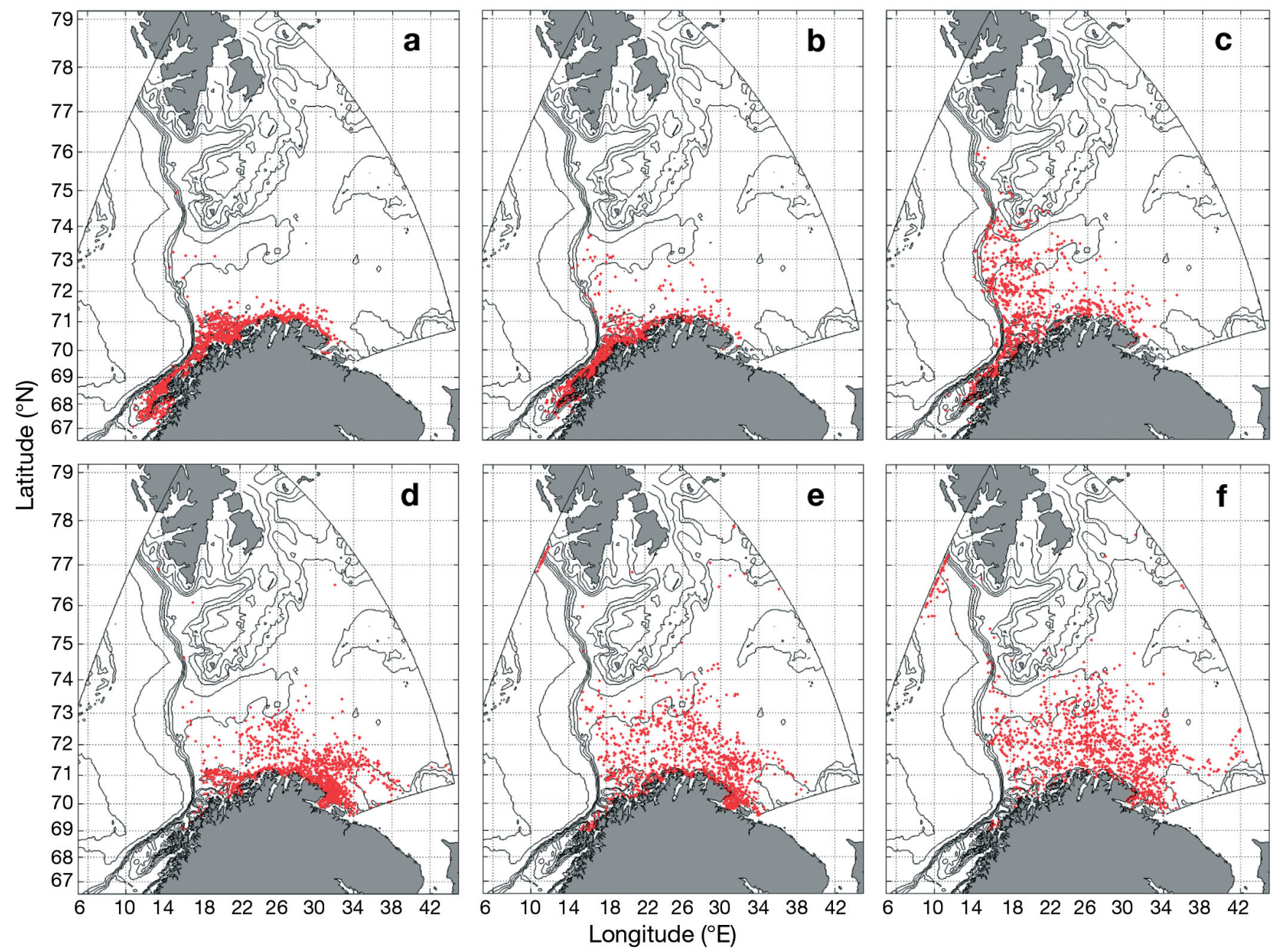

Fig. 4. Gadus morhua. The effect of risk sensitivity of vertical migration on larval dispersal. Each point represents the position of 1 larva after $100 \mathrm{~d}$ of drift from Vestfjorden $(\mathrm{a}-\mathrm{c})$ and Moskenesgrunnen $(\mathrm{d}-\mathrm{f})$ for $\pi_{i}$ equals 1 (fearful larvae) $(\mathrm{a}, \mathrm{d}), 0.5$ (median risk sensitivity) (b,e) and 0 (bold larvae) (c,f). For each level of risk sensitivity, 50 individuals were released at the same time and place, with variability in drift paths introduced by minor spatial and temporal perturbations at the release point

Finally, we estimated the fitness for larvae switching between 2 risk sensitivities at 8 possible sizes (Rule 2; Fig. 6), by releasing 50 larvae at each level of risk sensitivity $(13 \times 13 \times 8)$. To assess fitness, we extracted the 50 individuals with the highest fitness, ensuring that they had an optimal late (or early) behavioural strategy. Larvae changing their strategy ontogenetically did slightly better than those following the same rule throughout the larval stage, for any size of switch (compare Figs. 5 \& 6). Larvae that changed their behaviour at an early ontogenetic stage emphasised growth $\left(\pi 1_{i}=0.25\right)$ before they shifted to a more risksensitive (fearful) behaviour $\left(\pi 2_{i}=0.75\right)$, in order to maximise their fitness (Fig. 6a,b). However, fitness was relatively flat across early risk sensitivity for larvae that switched early. A later switch favoured more fearful strategies also during the early stage (Fig. 6c,d). The similarity between the shape of the fitness curves for the 2 release sites is encouraging, as it suggests that strategies may be quite robust across different spawning grounds.

\section{DISCUSSION}

An important topic for general population and community ecology is to model organisms with flexible individual behaviour, motivated through individual states and environmental cues (Giske et al. 2003, Persson \& De Roos 2003, Grimm \& Railsback 2005). Here, we have explored 2 simple individual decision rules and their consequences for growth, mortality and drift trajectories of pelagic larval fish. The model experiments demonstrated that rules for larval vertical positioning have consequences on several scales. Locally, depth selection affects instantaneous mortality and 
Fig. 5. Gadus morhua. Comparison of fitness consequences for larvae drifting from 2 spawning locations (a) with various fixed attitudes to risk using Rule 1 and (b) staying at fixed depths. Larvae from Moskenesgrunnen are indicated by blue squares and Vestfjorden by red circles. There are 4 curves for each of the spawning grounds, indicating the single most successful larvae, the top 10 and $25 \%$, and the average overall larvae (indicated by increasing size in circles and squares). Fitness is measured as accumulated survival probability of larvae when they reach a length of $18 \mathrm{~mm}$

Fig. 6. Gadus morhua. Comparison of fitness consequences of strategies that vary in risk sensitivity using Rule 2 . Results are shown for 2 spawning locations (Moskenesgrunnen by blue squares and Vestfjorden by red circles). The panels show fitness consequences of changing strategy at $(a, b)$ $6 \mathrm{~mm}$ and (c,d) $16 \mathrm{~mm}$; left panels are early risk sensitivity (given optimal risk sensitivity in the second period) and right panels show the effect of late risk sensitivity (given that early risk sensitivity is optimal). There are 4 curves for each of the spawning grounds, indicating the single most successful larvae, the top 10 and $25 \%$, and the average over all larvae (indicated by increasing size in circles and squares). Fitness is measured as accumulated survival probability of larvae up to a length of $18 \mathrm{~mm}$
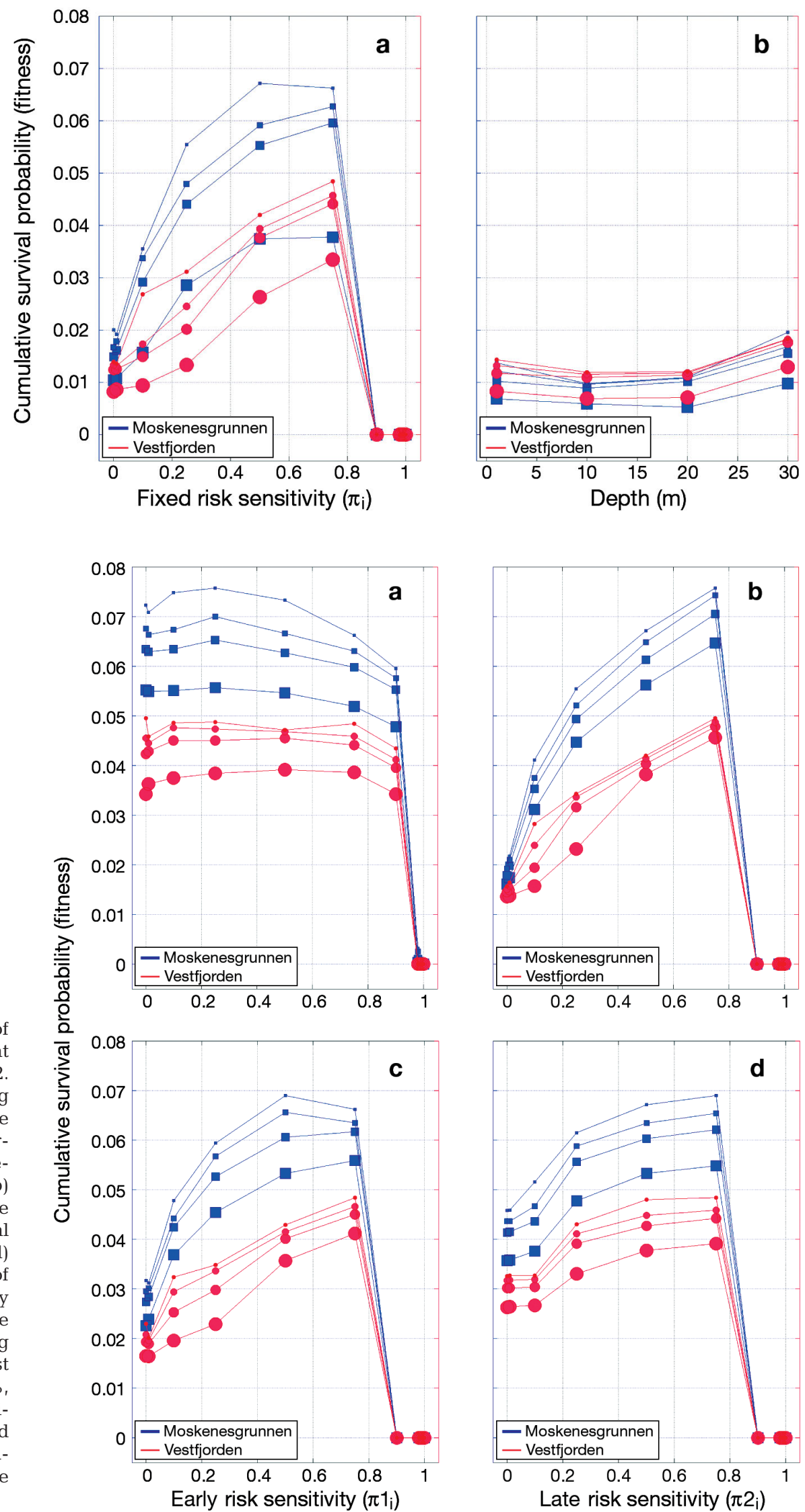
growth rates, leading to higher survival through the larval period compared to larvae that were forced to stay at fixed depths. However, the strategy for depth selection also has long-term and large-scale consequences. First, since vertical migration interacts with ocean circulation, the strategy influences which drift trajectory a larva will follow and thereby the physical environment the larva experiences along its way. This means that the behavioural strategy, leading to a certain drift trajectory, has delayed effects on growth and survival, since temperature and light conditions vary according to the particular route. Temperature will affect growth rates directly, as physiological processes are faster in warmer water for the range observed in the model area. In turn, this will have indirect consequences for mortality, since fast-growing larvae spend less time in the size window where they are vulnerable to predation and since their ability to move vertically and thereby manipulate predation rates by fish increases with size. On the other hand, at higher temperatures, the predators of larvae will have higher metabolic rates and require more food. However, predation on larvae is not temperature dependant in our model at this stage. Other factors, for example the spatial and vertical distribution of predators and prey, will influence growth and survival in similar ways, but were not included in this model. Second, the area or region where the larvae end up after the drift phase can have important consequences for later life stages (Cowen et al. 2006). Not only does habitat type and climate vary geographically, but currents and distance can preclude the use of essential feeding and spawning sites later in life.

While the importance of vertical positioning has been realised in many coupled bio-physical models (e.g. Hinckley et al. 1996, Werner et al. 1996, Fox et al. 2006), this is the first attempt to model larvae that select depths based on an inherent trade-off rule between growth and mortality in a general circulation model. This involves giving larvae an individual opportunity to respond to the processes affecting immediate growth and mortality, rather than imposing vertical distribution as an assumption of the model. We tested 2 simple rule formulations, each with the full range of strategies from maximising immediate growth to maximising immediate survival. Both rules gave better fitness than for non-responsive individuals drifting at fixed depths. Both spawning grounds favoured active vertical migration, and an intermediate risk sensitivity seemed to be optimal under the assumptions given here. When risk sensitivity was allowed to change with ontogeny, larvae that emphasised growth first and then changed to an intermediate risk sensitivity at an early ontogenetic stage were the most successful ones. However, it appears that Rule 2 only slightly improved fitness compared to the simpler Rule 1, where larvae used the same risk sensitivity throughout.

Both growth and mortality depend on complex processes that link the physical environment and the distribution of predators and prey with behaviour and internal physiology. These processes must necessarily be simplified in models, and our results are likely to be sensitive to a number of parameters used in the different submodels. Especially, the benefit of behaviour is tightly linked to how mortality is modelled. Behaviour influences light exposure and therefore encounter rates with visual predators, but does not affect predation from invertebrates, which we have modelled as a purely size-dependent mortality that is high for small larvae and declining with size (McGurk 1986). Predation rates from invertebrates and fish are comparable at a larval length of about $9 \mathrm{~mm}$, but above this length fish predation dominates. That fish predation plays a major role is supported by the strong indications that pelagic fish regulate the recruitment success of cod (Köster \& Möllmann 2000, Swain \& Sinclair 2000). In addition to cannibalism, both herring and capelin are abundant in the drift routes of Northeast Arctic cod Gadus morhua and are known to forage on cod larvae.

The purely size-determined mortality rate in our model is lower than the mortality rate in the empirical model compiled by McGurk (1986) for larvae < $13 \mathrm{~mm}$ and slightly higher for larger larvae. Sundby et al. (1989) estimated the average daily mortality rate to be about 0.2 , which is about 4 times higher than the mortality rate applied here (and thus also 4 times higher than the mortality rate used by McGurk [1986] for $13 \mathrm{~mm}$ larvae). However, survival probabilities (from hatching to $15 \mathrm{~mm}$ ) on the order of $10^{-2}$ are probably too high, given that the mean annual egg production is around 1 to 2 million eggs per female (Kjesbu et al. 1996). The motivation for vertical migration is largely determined by the strength of predation from invertebrates relative to predation from fish. Increasing the invertebrate predation rate $\left(\mu_{\mathrm{n}}\right)$ would make fish predation, the only depth-dependent component of mortality, less important. Larvae that grow faster would have higher survival probabilities, increasing the reward on rapid growth. Simulations (not shown here) indicate that the optimal $\pi_{i}$ is then shifted to the left (from $\pi_{i}=0.5-0.75$ to $0.25-0.5$ ), favouring larvae with a shallower vertical distribution and with average depths of between 20 and $40 \mathrm{~m}$ in late ontogeny. Drifting at a fixed shallow depth will then result in a comparable fitness to individuals with active vertical migration, because exposure to higher mortality rates during early ontogeny in order to shorten this vulnerable stage becomes a good strategy. However, very little is known about the distribution of risk among 
visual and non-visual predators, and only additional process-oriented field studies can improve our knowledge on this.

We have assumed that growth is a function of temperature and light, ignoring both spatial and temporal variability in prey distribution. The main prey items for larval cod are nauplii and copepodite stages of Calanus finmarchicus, and the production and abundance of these, in turn, depend on factors such as female abundance and primary productivity. These prey are also known to perform diel vertical migration; differences in vertical distribution between day and night of up to $20 \mathrm{~m}$ have been observed (Tilseth \& Ellertsen 1984). Future refinements of the present analysis will be to include zooplankton models or assimilate data on prey abundance and distribution.

In the present study, we initialised larvae at hatching although Northeast Arctic cod has an egg stage lasting up to $3 \mathrm{wk}$. The transport of eggs is purely a function of egg density and ocean physics (Sundby 1997). The actual density of the eggs, including the chorion membrane and the amount of yolk and buoyant fat, may have evolved as a trade-off between predation risk and advection consequences of vertical positioning due to density gradients. Incorporating drifting eggs explicitly would perhaps change the initial dispersal of eggs and could therefore precondition initial larval distribution differently than what is presented here.

The modelled larvae swim to their preferred depth and are not affected by vertical mixing. Clearly this is a simplification, as vertical mixing may make it more difficult to remain at the preferred depth. However, a dynamical vertical positioning of individual cod larvae depends on the density equivalent of each larva relative to the stratification of the water column and the vertical mixing coefficient, which vary both in time and space. This could be implemented by following the numerical recipe by Thygesen \& Adlandsvik (2007, this TS). Under strong mixing, larvae with similar state and risk sensitivity would then have a broader vertical distribution.

Another complicating factor we have ignored is the consequence to fitness of drifting off to unfavourable settlement habitats (Fiksen et al. 2007). Although little is known about what determines the quality of settlement areas, it might be possible to combine spatial data from 0-group surveys (Dingsør 2005) with data on later stages from winter cruises to derive information about how fitness depends on geographical position at settlement (Dingsør 2006).

Observations on vertical migration by cod larvae and the corresponding distribution patterns are limited, but those described in literature indicate that diel migration occurs, depending on larval size and oceanographic conditions (Ellertsen et al. 1984, Neilson \&
Perry 1990, Lough \& Potter 1993). Lough \& Potter (1993) reported that Atlantic cod larvae on Georges Bank of $>6 \mathrm{~mm}$ length were capable of regulating their depth when vertical mixing was low. The ability to control their depth and the extent of diel migration increased with larval size, while the mean daily depth increased throughout ontogeny until they settled close to the seabed. Similarly, Ellertsen et al. (1984) observed diel migrations in first-feeding Northeast Artic cod larvae. The larvae concentrated between 5 and $10 \mathrm{~m}$ during the night and spread out between 5 and $35 \mathrm{~m}$ during the day. The strong interaction between vertical positioning and horizontal ocean transport documented in this study suggests that further field observations of vertical distribution and its change with ontogeny should be a priority of future surveys. If possible, parallel recordings of other individual characteristics in the field, such as stomach fullness, swimming direction and speed, and activity level, could also guide both the further development of models coupling behaviour with oceanography, as well as our understanding of the ecology of early life stages.

The current analysis must be viewed as an initial exploration and an example of how simple behavioural rules can be used in combination with ocean models to study the interaction between local and strategic trade-offs in larval fish behaviour. We have only looked at 2 potential spawning grounds, and strategies may be very different when drift trajectories from further spawning grounds are included. A complete analysis of behavioural strategies would therefore need to take the whole geographical spawning range into account. To evaluate the success of a strategy, one should also assess parental spawning strategies, including migration costs, and repeat the analysis with physical forcing for several years to investigate environmental effects.

This study illustrates how adaptive habitat selection under realistic assumptions of local vertical gradients of growth and predation risk interacts with horizontal advection of larval fish. It serves as an example of how behavioural ecology can provide methods to improve the predictive and explanatory power of individualbased models for larval fish and to develop a generic approach for other marine species with pelagic larval stages. The coupled larval IBM and ocean circulation model represents a virtual laboratory that can prime our intuition and develop our understanding of processes and their relative importance throughout ontogeny. We are confident that this undertaking will provide hypotheses and direct future field and experimental studies. More specifically, the model also suggests a set of robust behavioural rules for vertical migration of Northeast Arctic cod that can be implemented in coupled IBM and ocean models and explored in laboratory experiments. 
Acknowledgements. This research was supported by the projects 'ECOBE' and 'Sustainable harvesting of marine resources', financed by the Research Council of Norway. Computer time for the hydrodynamical model was partly granted by NOTUR: the super-computing programme of the Research Council of Norway. NOAA-CIRES Climate Diagnostics Center, Boulder, Colorado, USA, provided data through the NCEP/NCAR reanalysis project (www.cdc.noaa.gov/). Thanks to S. Eliassen and T. Torgersen for discussions and comments.

\section{LITERATURE CITED}

Ådlandsvik B, Sundby S (1994) Modelling the transport of cod larvae from the Lofoten area. ICES Mar Sci Symp 198: 379-392

Aksnes DL, Giske J (1993) A theoretical model of aquatic visual feeding. Ecol Model 67:233-250

Aksnes DL, Utne ACW (1997) A revised model of visual range in fish. Sarsia 82:137-147

Bailey KM, Houde ED (1989) Predation on eggs and larvae of marine fishes and the recruitment problem. Adv Mar Biol 25:1-83

Clark CW, Mangel M (2000) Dynamic state variable models in ecology: methods and applications. Oxford University Press, New York

Clark DL, Leis JM, Hay AC, Trnski T (2005) Swimming ontogeny of larvae of four temperate marine fishes. Mar Ecol Prog Ser 292:287-300

Cowen RK, Paris CB, Srinivasan A (2006) Scaling connectivity in marine populations. Science 311:522-527

Dingsør GE (2005) Estimating abundance indices from the international 0-group fish survey in the Barents Sea. Fish Res 72:205-218

Dingsør GE (2006) Influence of spawning stock size and environment on abundance and survival of juveniles in commercially important fish stocks in the Barents Sea. PhD thesis, University of Bergen

Ellertsen B, Fossum P, Solemdal P, Sundby S, Tilseth S (1984) A case study on the distribution of cod larvae and availability of prey organisms in relation to physical processes in Lofoten. In: Dahl E, Danielssen D, Moksness E, Solemdal P (eds) The propagation of cod. Flødevigen Rapp $1: 453-478$

Engedahl H, Ådlandsvik B, Martinsen EA (1998) Production of monthly mean climatological archives of salinity, temperature, current and sea level for the Nordic Seas. J Mar Syst 14:1-26

Ezer T, Arango HG, Shchepetkin AF (2002) Developments in terrain-following ocean models: intercomparisons of numerical aspects. Ocean Model 4:249-267

Fiksen $\varnothing$ (1997) Allocation patterns and diel vertical migration: modeling the optimal Daphnia. Ecology 78:1446-1456

Fiksen $\varnothing$, Folkvord A (1999) Modelling growth and ingestion processes in herring Clupea harengus larvae. Mar Ecol Prog Ser 184:273-289

Fiksen Ø, MacKenzie BR (2002) Process-based models of feeding and prey selection in larval fish. Mar Ecol Prog Ser 243:151-164

Fiksen Ø, Utne ACW, Aksnes DL, Eiane K, Helvik JV, Sundby S (1998) Modelling the influence of light, turbulence and ontogeny on ingestion rates in larval cod and herring. Fish Oceanogr 7:355-363

Fiksen $\varnothing$, Aksnes DL, Flyum MH, Giske J (2002) The influence of turbidity on growth and survival of fish larvae: a numerical analysis. Hydrobiologia 484:49-59
Fiksen Ø, Eliassen S, Titelman J (2005) Multiple predators in the pelagic: modelling behavioural cascades. J Anim Ecol 74:423-429

Fiksen Ø, Jørgensen C, Kristiansen T, Vikebø F, Huse G (2007) Linking behavioural ecology and oceanography: larval behaviour determines growth, mortality and dispersal. Mar Ecol Prog Ser 347:195-205

Finn RN, Rønnestad I, van der Meeren T, Fyhn HJ (2002) Fuel and metabolic scaling during the early life stages of Atlantic cod Gadus morhua. Mar Ecol Prog Ser 243:217-234

Folkvord A (2005) Comparison of size-at-age of larval Atlantic cod (Gadus morhua) from different populations based on size- and temperature-dependent growth models. Can J Fish Aquat Sci 62:1037-1052

Fox CJ, McCloghrie P, Young EF, Nash RDM (2006) The importance of individual behaviour for successful settlement of juvenile plaice (Pleuronectes platessa L.): a modelling and field study in the eastern Irish Sea. Fish Oceanogr 15:301-313

Giske J, Mangel M, Jakobsen P, Huse G, Wilcox C, Strand E (2003) Explicit trade-off rules in proximate adaptive agents. Evol Ecol Res 5:835-865

Grimm V, Railsback S (2005) Individual based modeling and ecology. Princeton University Press, Princeton, NJ

Hinckley S, Hermann AJ, Megrey BA (1996) Development of a spatially explicit, individual-based model of marine fish early life history. Mar Ecol Prog Ser 139:47-68

Hinckley S, Hermann AJ, Mier KL, Megrey BA (2001) Importance of spawning location and timing to successful transport to nursery areas: a simulation study of Gulf of Alaska walleye pollock. ICES J Mar Sci 58:1042-1052

Hinrichsen HH, Möllmann C, Voss R, Köster FW, Kornilovs G (2002) Biophysical modeling of larval Baltic cod (Gadus morhua) growth and survival. Can J Fish Aquat Sci 59: $1858-1873$

Houston A, McNamara J (1999) Models of adaptive behaviour. Cambridge University Press, Cambridge

Huggett J, Fréon P, Mullon C, Penven P (2003) Modelling the transport success of anchovy Engraulis encrasicolus eggs and larvae in the southern Benguela: the effect of spatiotemporal spawning patterns. Mar Ecol Prog Ser 250: $247-262$

Huse G (2001) Modelling habitat choice in fish using adapted random walk. Sarsia 86:477-483

Kalnay E, Kanamitsu M, Kistler R, Collins W and 18 others (1996) The NCEP/NCAR 40-year reanalysis project. Bull Am Meteorol Soc 77:437-471

Kjesbu OS, Solemdal P, Bratland P, Fonn M (1996) Variation in annual egg production in individual captive Atlantic cod (Gadus morhua). Can J Fish Aquat Sci 53:610-620

Köster FW, Möllmann C (2000) Trophodynamic control by clupeid predators on recruitment success in Baltic cod? ICES J Mar Sci 57:310-323

Kristiansen T, Fiksen $\varnothing$, Folkvord A (2007) Modelling feeding, growth and habitat selection in larval cod: observations and model predictions in a macrocosm environment. Can J Fish Aquat Sci 64:136-151

Leis JM, Hay AC, Trnski T (2006) In situ ontogeny of behaviour in pelagic larvae of three temperate, marine, demersal fishes. Mar Biol 148:655-669

Lough RG, Potter DC (1993) Vertical distribution patterns and diel migrations of larval and juvenile haddock Melanogrammus aeglefinus and Atlantic cod Gadus morhua on Georges Bank. Fish Bull 911:281-303

McGurk MD (1986) Natural mortality of marine pelagic fish eggs and larvae: role of spatial patchiness. Mar Ecol Prog Ser 34:227-242 
Mullon C, Cury P, Penven P (2002) Evolutionary individualbased model for the recruitment of anchovy (Engraulis capensis) in the southern Benguela. Can J Fish Aquat Sci 59:910-922

Neilson JD, Perry RI (1990) Diel vertical migrations of marine fishes - an obligate or facultative process. Adv Mar Biol 26:115-168

Otterlei E, Nyhammer G, Folkvord A, Stefansson SO (1999) Temperature- and size-dependent growth of larval and early juvenile Atlantic cod (Gadus morhua): a comparative study of Norwegian coastal cod and northeast Arctic cod. Can J Fish Aquat Sci 56:2099-2111

Persson L, De Roos AM (2003) Adaptive habitat use in sizestructured populations: linking individual behavior to population processes. Ecology 84:1129-1139

Ramsden D, Holloway G (1991) Timestepping Lagrangian particles in two dimensional Eulerian flow fields. J Comput Phys 95:101-116

Santos AMP, Re P, Dos Santos A, Peliz A (2006) Vertical distribution of the European sardine (Sardina pilchardus) larvae and its implications for their survival. J Plankton Res 28:523-532

Shchepetkin AF, McWilliams JC (2003) A method for computing horizontal pressure-gradient force in an oceanic model with a non-aligned vertical. J Geophys Res 108: 1-34

Shchepetkin AF, McWilliams JC (2005) The regional oceanic modeling system (ROMS): a split-explicit, free-surface, topography-following-coordinate oceanic model. Ocean Model 9:347-404

Skartveit A, Olseth JA (1988) Varighetstabeller for timevis

Editorial responsibility: Alejandro Gallego (Contributing

Editor), Aberdeen, UK belysning mot 5 flater på 16 norske stasjoner. University of Bergen

Strand E, Huse G, Giske J (2002) Artificial evolution of life history and behavior. Am Nat 159:624-644

Sundby S (1997) Turbulence and ichthyoplankton: influence on vertical distributions and encounter rates. Sci Mar 61: $159-176$

Sundby S, Bjørke H, Soldal AV, Olsen S (1989) Mortality rates during the early life stages and year class strength of the North-East Arctic cod (Gadus morhua L.). Rapp P-V Reun Cons Int Explor Mer 191:351-358

Swain DP, Sinclair AF (2000) Pelagic fishes and the cod recruitment dilemma in the Northwest Atlantic. Can J Fish Aquat Sci 57:1321-1325

Tilseth S, Ellertsen B (1984) The detection and distribution of larval Arcto-Norwegian cod, Gadus morhua, food organisms by an in situ particle counter. Fish Bull 82:141-156

Thygesen UH, Ådlandsvik B (2007) Simulating vertical turbulent dispersal with finite volumes and binned random walks. Mar Ecol Prog Ser 347:145-153

Vikebø F, Sundby S, Ådlandsvik B, Fiksen Ø (2005) The combined effect of transport and temperature on distribution and growth of larvae and pelagic juveniles of ArctoNorwegian cod. ICES J Mar Sci 62:1375-1386

Werner FE, Perry RI, Lough RG, Naimie CE (1996) Trophodynamic and advective influences on Georges Bank larval cod and haddock. Deep-Sea Res II 43:1793-1822

Werner FE, Quinlan JA, Lough RG, Lynch DR (2001) Spatially-explicit individual based modeling of marine populations: a review of the advances in the 1990s. Sarsia 86:411-421

Submitted: July 20, 2006; Accepted: April 30, 2007

Proofs received from author(s): September 5, 2007 